\title{
But It's My Money! Some Thoughts on the Ethics and Culture of Donating Money
}

\begin{abstract}
This chapter is the posthumous transcript of a public talk given at a workshop on religious perspectives on effective altruism. It explores the practice of charitable giving and comments on it from a moral perspective. It discusses the motives for donating to charity as well as the obligation to do so. It then considers a number of open questions about donations: the when, the how, and the how much. While the chapter is supportive of the obligation to give in general, it also considers two challenges to the present culture of donating: effective altruism and the call for replacing donations by social investments. The effective altruist approach is questioned on account of giving too much space to the task of doing good and missing out on aspects of the good life apart from morality. If people instrumentalize themselves for the sake of a better world, they risk missing the meaning of life.
\end{abstract}

Editorial Comment: Markus Huppenbauer, one of the co-editors of this volume, sadly passed away before this book could be completed. He planned to write his own contribution by building on the public talk with which he opened the workshop that forms the basis of this volume. Regrettably, he never got the chance to do so. After careful deliberation, we decided to publish a translated transcript of his talk. It has been lightly edited to adapt its spoken, personal, and spontaneous style for the purposes of a book chapter, and occasionally to leave out examples from the local context that are not relevant to the general argument. However, readers should bear in mind that the style and content were clearly geared towards a public lecture and have not been essentially changed. The transcription has been done by Arianna Lanfranchi and the translation is the work of Sarah Kirkby, both of whom we would like to thank for their efforts.

Today I would like to speak about the ethics and culture of donating money. The reference to ethics and culture provides a clue that this will not be a purely philosophical lecture, but I will, at times, be inspired by considerations from moral psychology and permit them to be part of my talk. "But it's my money!": whenever I hear that, I have a picture in my head of people sitting on pots of money, not wanting to part with any of it, and then one day dying and not being able to take it with them. And the question is: Does money actually belong to us? Is it something that we are allowed to sit on? Is it something that we have a right to? Or is there some kind of duty to donate? This is what interests me. And I am prepared to stick my neck out at this early stage in my lecture and say: yes, a duty to donate does exist, and donating a considerable amount of money is good. But more about that later.

I would like to begin by defining donations, a topic concerning which there is not much (philosophical) literature available. In the context of effective altruism (EA) there is some, but otherwise very little. Some very 
complex theories exist about duties to assist, of course, which donating would fall under, but I have found very little on donating itself, in either German or English. My definition is as follows: a donation is a voluntary contribution to a religious, scientific, charitable, cultural, economic, or political cause. Recipients of donations can be non-profit organisations, foundations, political parties, aid associations or religious communities. Donations can be financial or material, or a refusal of money in return for work performed, i.e. donations of time. This definition will accompany us as we proceed today, and I shall not be questioning it further. Maybe there are some specialists who could, but my primary concern will be to investigate the question: is there such a thing as a moral obligation to donate? And, if so, what does that mean?

Let us start by taking a look at the reality in Switzerland. The Swiss donate money to many different causes, and they donate a great deal. According ZEWO's statistics, in 2017, they donated a total of CHF 1.84 billion to various organisations. ${ }^{1}$ To me, that seems relatively high, and yet the total for the US is approximately $\$ 400$ billion, which is more. It is also interesting to look at the breakdown of the overall volume. Studies in Germany have shown that more and more money is being donated in total, but by fewer and fewer individuals. And studies also show that it is mainly people over the age of 60 who donate in the classic sense. Such statistics should be handled with care, however, because they do not include crowdfunding or other newer methods of donating. What we can say with certainty: donations are increasing, but the age group donating the money will soon be elderly and die, leading many to fear that the bottom will then fall out of this model.

What I would like to look at with you today is the following issues: firstly, motives and reasons for donating; secondly, the potential existence of a moral obligation to donate; thirdly, some specific practical questions regarding the when, how, and how much of donating - actually more important than the question regarding a moral obligation, to which the answer is relatively clear; fourthly, two challenges to the present culture of donating, namely EA and a movement which advocates social investment instead of donation. Following this exploration, I shall conclude with a few brief comments.

I have been through the literature for clues and have also - but not in the sense of an empirical investigation - asked various individuals: why do you donate? And yet people are reluctant to answer this question, as if asking 
them whether they donate could be akin to asking them whether they still have sex or how much they earn. Two more questions that the Swiss, at least, are loath to answer. Nevertheless, many people do donate, and their reasons and motivation for doing so vary tremendously.

I would like to start with a classic, namely feeling directly moved by the plight of others. This has very traditional roots and a pertinent religious narrative, the parable of the Good Samaritan to be found in Luke 10:25. You all know this story. A man has been attacked by robbers and is lying on the ground injured, bleeding and unconscious, with no money or anything else left to him. Two representatives of the cultural, political and religious elite march swiftly past, but cannot stop to help him because they have more important things to do. Their life goals collide with the needs of this man, and so they walk on by. What makes this story interesting: it is a Samaritan, somebody who does not belong to the elite and is in fact more of an outcast, who takes care of the injured man, nurses him, brings him to the next inn and makes sure that he gets something to eat and a place to sleep.

If you read this parable - which really is worth it, the story is fascinating - you will see that the arrival of the passer-by is described as follows: a Samaritan was passing, saw him, and was moved by what he saw. In most translations, it says "took pity on him", and the point here is not that he is moved on the inside, but that he takes action on account of something outside himself, namely the plight of another. It is the suffering of another which moves him to act. And I believe that many people make donations or offer assistance on this basis.

Another response you will frequently encounter is that some people just like giving. There is a good psychological explanation for this. A further factor that should not be discounted is economic gain. In Switzerland, it is financially beneficial to make donations. If you have an income that puts you into a higher tax bracket - maybe because you and your spouse are both earning well - then above a certain given level it is worth making donations. And the more income you have, the more it is worth it. I should think that utilitarians would be fine with donations on this basis. Motivation is not important; what is important is the result.

Another source of motivation you often hear about is gratitude: I am fine; I am lucky enough to live in a country where most people are fine; I did nothing to deserve this; it is not my own doing. And then people usually say that they want to give something back, so their motivation is gratitude. 
Of course, there might also be ethical reasons for donating, in a narrow sense of the word. It is imperative that we support and help those in need. It is a moral obligation. But why? Because it is unfair for one person to be living in such good circumstances and another, through no fault of their own, in such bad circumstances. This puts us right at the centre of the ethical discourse. I am not concerned here with something as orientationally abstract as rules; I am far more interested in something else, namely considerations or feelings. It is a religious imperative to be charitable. In all religious traditions, helping those in need - in the Old Testament especially widows, orphans, the poor and strangers - is a very important aspect of our interactions. We must give to those who fall through the normal structures of society. That is clear, and in the Christian tradition it is the will of God. Analogous traditions also exist in the Hindu, Buddhist and of course Muslim cultures.

These, then, are some of the motives and reasons why people donate money. Obviously, many people do donate, but I would like to briefly question whether or not they must. If nobody were to donate, could we demand that people should? I shall outline this point very roughly.

There is no doubt that human beings have moral obligations: duties to do certain things, and duties not to do others, for example not to kill or torture, to respect the property of others, to treat others fairly, etc. We do not need to expand on this further. What interests me here is: alongside the moral obligations mentioned above, which I assume to exist as a matter of course, is there also a moral obligation to donate? It would be easy if we could say that donating is morally equally as imperative as, for example, respecting the property of others. To which my gut response is: "yes, but...”. I could also take "no, but..." as my starting point, but I choose the former over the latter. What is crucial here is the but.

So we have a duty to donate. In order to arrive at this statement, it is necessary to introduce a differentiation to aid our understanding of what exactly we are talking about when we talk about donating. The duty to donate belongs to the larger class of duties to assist. And, viewed formally, it is a positive obligation. Positive obligations - and here I refer to Corinna Mieth $^{2}$ - are concerned with the active causation of certain improvements. When I help somebody, I actively contribute to making things better for that person. In contrast: if I do not kill somebody, I passively refrain from doing something in a negative sense. Donating is obviously an obligation from the class of positive obligations. And we will see in a moment why 
that is relevant. As far as I can see, the most comprehensive class of positive obligations is the class of duties to assist, in other words, duties to help other people. Their foundations may vary, for example, human dignity or respect for others, but that is not important here. A duty clearly exists - as stated by philosophers from Kant to Peter Schaber to Corinna Mieth, and also by utilitarians - to assist other people and offer help if they require it.

And donating, this is my hypothesis, is one possible way of fulfilling this obligation. Further ways of helping others also exist, not just donating, and that is why my response was: "yes, but...".

These duties to assist (in a very broad sense of the term) involve an interesting aspect. On the one hand, there are some duties to assist where it is completely clear what we must do. A famous example comes from Peter Singer: a child is drowning in a nearby pond, and of course, we have a duty to save the child. ${ }^{3}$ We do not even have to stop and think about what assistance might mean. But there are other situations in which the meaning is not so clear.

If for example - as my hypothesis purports - it is the goal of assistance to support people in order to enable them to lead a decent life, then, when people are not currently in need, assistance can mean a lot of different things. Positive obligations are obligations that we must fulfil actively, but they also (when there is no emergency situation) leave a certain amount of scope as to how we fulfil them. Donating - to my mind - is one possible way of fulfilling our moral obligation to help other people. (And also, incidentally, to help other animals - that is specifically sentient animals - and this is highly significant in the field of utilitarianism.) The goal of assistance or of such obligations - in other words, the why behind the obligation - is, then, to support people to enable them to lead a decent life. The means to this end is a society based on solidarity. And in a society based on solidarity - this is my belief - donating is part of the culture surrounding our response to people in need. Maybe that was a little hurried, but I think it will suffice for now. To sum up thus far: we have duties to assist others, which I will specify further later on, and donating is one possible way of performing such duties.

When should we donate? This brings us to differences that obviously exist in connection with assisting other people. On the one hand, we have what Mieth calls strong duties of assistance in emergency cases (starke Nothilfepflichten). "Strong" because there is no doubt that something must be done - for example, aid following a catastrophe. More generally

3 Singer, "Famine, Affluence, and Morality." 
speaking, we could say that we are concerned here with people in need through no fault of their own. This is the obligation which we have to help in an emergency.

Then we have what Mieth calls weaker duties of beneficence (schwächere Wohltätigkeitspflichten). The German expression Wohltätigkeit is rather an outdated word and I have looked for alternatives in German, and I have opted instead for the expression "development aid" (Entwicklungshilfe). I understand this expression in a very broad sense - that is, not in the sense of development aid where, for example, Swiss people go to Ghana and build latrines. That is also an interesting topic, but I mean development aid in the sense that we support people in order to enable them to lead a decent life. These are developmental processes that need to be generated, so to speak.

Finally, there is another thing which I would also include within the category of duties to assist. Though this is a more difficult case, and the exact categorisation is not clear. We can make donations, financing and facilitating projects which the state either cannot finance or does not wish to finance. Many institutions only function because there are people or foundations ensuring that they can operate. And the question is, of course, whether in this context we can still speak of an obligation. Firstly, it is certainly necessary to differentiate between donating and sponsoring. If a company like the Swiss bank UBS finances an art exhibition at the Fondation Beyeler near Basel, then that is very nice for the public because we can all go and look at the pictures exhibited, but it is also very nice for UBS because they can build up their reputation and polish their image. By the way: I am not all that interested in the motivation of UBS, as long as I can look at the pictures. But we must make this difference: donating, patronage, philanthropy, etc. are completely different from sponsoring, where the person (or more usually a company) directly profits in terms of its reputation. My inclination is to say that such funding in place of the state does happen in the donations marketplace, but that there is no moral obligation to perform it. Whereas both strong duties of emergency assistance and weaker duties of beneficence really do involve moral obligations, the financing of projects in lieu of the state is - as philosophers would put it - supererogatory. That sounds a little strange but it simply means that one does not have to do it. If one chooses to, then that is nice. If someone chooses to donate wealth gained in the market economy, then it is a good thing to pass on that wealth and not just sit on it. These are my rough thoughts on "When should we donate?". In the remainder, I want to focus primarily on strong duties of emergency assistance and weaker duties of beneficence. 
Now we are drawing closer to the matter at hand: how should we donate? We are not yet contemplating how much - to which the answer will naturally be: much - but simply how. In which spirit should donating take place? There are three points which I believe to be of utmost importance here. Firstly, it seems to me relatively clear, at least in our part of the world, that donating should not occur in an arrogant, paternalistic spirit giving handouts condescendingly. Maybe some of you are still familiar with the old-fashioned missionary collection boxes: when you insert a coin, the black figure on the top of the box nods in gratitude. This is, of course, a relic of the past. Today - for emergency assistance, too, but primarily for development aid - to donate means to help others to help themselves. We make it possible for people to stand on their own two feet. Although I used missionary collection boxes as a negative example here, it tended to be the more liberal missionary societies in Switzerland, in Germany, also in the UK and the US, who recognised very early on - as early as the 1960 s - that development aid cannot be a one-way street. In other words: it cannot be the case that we - the rich in the West - give money to you the poor people in the South - so that you can lead a decent life; instead, any movement must be bidirectional. This is a point which many church aid societies recognised long before state development aid programmes. Empowerment is crucial.

Secondly, for many development aid projects, donating makes sense above all when something is not simply given to people, but when those people are involved and included in joint projects. There are hundreds, even thousands of development projects in which unbelievable amounts of money have gone down the drain because the givers thought they knew best how to help. Technology was brought, money was brought, and it did not work. And often the reason it did not work was that, while a great deal of money had been brought, no attention had been paid to integrating the local people receiving the aid, enabling them to continue alone with these projects once the money had run out.

Here is a little example: I grew up in Ghana, and today I am on the advisory council of the Ernst Peyer Foundation. In some regions of Ghana, we focus on hand pumps for wells; in other words, hygiene for latrines, very basic things. If the people there do not have these basics, death is never far off, and, therefore, I believe it is a truly effective way of helping. We do not simply go to Ghana and build latrines; instead, we select a village or region, and then the people in the village or community must show us what they can contribute to the building of a hand pump or a latrine. That can be money - usually, we actually demand that they make at least a 
small financial contribution - but essentially it means workers and working hours. Workers from outside are not paid to build the latrines; the people have to do it themselves, making them genuinely involved in the project. This contributes to its sustainability in the long run.

And last but not least: donating has to be efficient! This is not something invented by EA, but something which has been in the foreground for, say, 30 years whenever talk has turned to donations and the financing of foundations. You must be efficient in the manner in which you deal with donated money. From 2000-2005, I managed the Swiss Study Foundation, and back then we had to raise a bit more than CHF 1 million. That was at a time when companies who had already been giving us money increasingly began to ask us: how much of the money do you take for administration? And if we had a budget that included $11 \%$ for administration costs, they no longer gave us money. At that time there was a clear line: under $10 \%$. This of course led to budgets being correspondingly corrected, which was not really a problem. But the idea that donations must be efficiently managed and distributed is actually quite old. A little more recent is EA, which looks not only at organisations themselves, in other words, how much money they use for administration purposes, but also at where does the donated money go. Where is the effect greatest?

And now to the last of these specific questions: how much should be donated? I think there is no doubt that most of us are not saints. Bearing this in mind, I believe that there is no moral obligation to donate so much that we ourselves end up not having enough. Self-sacrifice or complete selflessness is presumably not something that anyone would morally demand. Let us look at a famous example involving a saint, namely Martin of Tours. One winter, a beggar who was freezing asked for help. Saint Martin (depicted on the back of a noble horse - but still) ripped his cloak in two and gave half to the beggar. And that for me is the true embodiment of assistance and what makes Martin so famous. It is a fascinating story because he gives a great deal of what he has in the said situation, but keeps back enough to ensure that he is still warm and will not freeze himself. He does not sacrifice himself in the process.

It is interesting to see what various websites say about this. In the context of Hinduism, for example, I have repeatedly come across the expression "selflessness". In connection with donating, this seems to be a very important category. By the way, when we speak about altruism later on, this is very akin to selflessness, a turning to others in a non-selfish way. 
So now we have reached the point where we can say: fine, we do not have to sacrifice ourselves, we just have to give as much as we can to still leave ourselves with enough - a sufficiency theory.

My co-organiser, Dominic Roser, pointed me towards the Methodist founder John Wesley and his way of dealing with money. It has been publicly reported that at the tender age of 30 he earned 30 pounds, of which he needed 28 and donated the other 2. Over the years he earned more and more, but his living costs remained the same. He was ultimately earning more than 1400 pounds, yet still only required 30 pounds to live on, donating the difference as before. This would be the sufficiency theory in action, and not something which could really be turned into an imperative for everyone. It would probably be too much to ask of most people. And to be clear about this: I like people, and I do not think we should demand things of them that go beyond what they can cope with. But it is not too much to ask of people that they donate at all, just as it is not too much to ask of them that they do not kill or torture. They can cope with demands like that. But to demand that they do what John Wesley did definitely goes too far. I would therefore say: tread a little carefully with demands. Nevertheless - and here I think I am in the same boat as the effective altruists - most inhabitants of the wealthier countries in the world could give much more than they actually do. And the next question is, of course, where is the limit? I do not believe there is one here; these are simply concepts that are currently discussed. But we should address the issue: at what point does it begin to be too much, and when is that just an excuse?

What we certainly need to remember in any discussion about aid and donations is that it is not me personally, and it is not only the rich who must save the world and donate as much as possible, but always the collective. As far as global poverty and other problems affecting the whole world are concerned, we do not have to improve the world as individuals, but together. This is one of the reasons why the theories of Peter Singer have been subject to criticism. And neither should we forget that, as citizens and taxpayers, we already support national aid programmes, which in turn contribute to tackling the problems at hand.

Now maybe you are thinking: "I need some more detail here. I have been to this lecture and listened to this ethicist talking about donating, but he failed to say how much I should donate. Some numbers would be good." Never forget that such numbers cannot be absolute: obviously, if people have a lot of money, they can donate a lot. 
Numbers are helpful and have been handed down through religious communities for a very long time. One famous example is Christian tithing, which was a tradition for centuries and practised by hundreds of millions of people. Paying a tithe simply means: I will pass on, in one way or another, the 10th part of anything which comes in. Islam has an analogous tradition set at about 2.5\%, the Zakat imperative, which is actually one of the most important aspects of being a Muslim. Such numbers can be helpful as an orientation. And the $10 \%$ guideline has recently been revived. The pledge of Giving What We Can, for example, states: "I pledge that from now until the day that I retire, I shall give at least ten-percent of my income to whichever organisations can most effectively use it to improve the lives of others." ${ }^{4}$

This is relatively new and is slowly directing us towards EA. I think it is amazing that a pledge like this exists, and that to date approximately 5000 people have signed up to it. I simply wish to point out that, over the last few hundred years, millions and millions of people have given one-tenth, so it is nothing new. It is nice to see this happening. It is the secular aspect that is new, and I state that deliberately. The reference to religious traditions also provides clues about how people managed to pay their tithes. What resources did they have, enabling them to do this?

So that was donating in a brief overview. We have seen that something akin to a moral obligation to help people exists, and that one possible way of doing that is donating. Furthermore, I think that in our cultural and social context donating is a sensible way of helping others for most people.

There are two challenges facing the classic notion of donating. One is EA, originally a philosophical movement and started by people like Peter Singer. But I am less concerned with its philosophical aspects and far more with the question: what can be said about EA from a religious or theological perspective?

At this point, I would like to offer a pertinent quotation by Peter Singer from the Austrian daily newspaper Der Kurier. ${ }^{5}$ The article was not about God, but about the world, and about animals. One of the - empirically correct - things the journalist said was: "the level of donations is increasing year by year. Many people are choosing to invest in emergency aid or other causes." I find it slightly embarrassing that the journalist talked about investing because it is not investing: with an investment I get something back. It is linguistically careless, but Peter Singer was generous to a fault and replied: "yes, many people are donating, and donations are rising steadily"

4 Giving What We Can, "Pledge to give more."

5 Klatzer, "Haben moralische Verantwortung." 
- that was the positive news, and now for the negative - "and yet a high percentage of that money does not bring the greatest benefit for society. We are wasting resources negligently." Donations are fast becoming resources, then. He then remained within this economic paradigm and continued by saying that it is excellent that people donate, but that they spend far too little time considering what they are donating to. The money raised could be put to far greater effect than it is at present. And that is the concept behind EA: of course, people should do good - they should provide help in whichever way - but they should do so better.

What does "better" mean in this context? This brings me to William MacAskill, who picks up on Peter Singer's statement and clarifies it further as follows: we have an obligation to help people, and when we act on this obligation it is important how we do so. We should not simply help, but should think about how we can help as efficiently as possible. The idea, in a nutshell, is that as many people as possible should be able to profit as efficiently as possible from the money made available. And how do we do this? By considering as impartially as possible how, for example, a sum of money can be donated to a place where it can do as much good as possible. Reading these texts, the issue at stake seems to be a matter of reason. If we help at all, then we should do so in such a way as to profit as many people as possible. Is that not obvious, and would not all reasonable human beings have to agree on this? And because we all agree, we clearly need scientific evidence to show us where the help is required and where our money can be used most effectively. This, in turn, means that we require investigations into the efficiency of various organisations, and also into the most efficient means of bringing about an improvement for the people who need it most.

And on first reading, I believe this to be a good idea. A considerable proportion of donating to date has been driven by emotion, it has to be said. We feel a connection to mountain farmers, so we make a donation to mountain farmers. Or, like me, we have a relationship to missions. I have supported missionary societies throughout my whole life and, while they have to fulfil certain criteria, Swiss organisations such as Brot für alle, Mission 21, or HEKS all receive something from me. I truly believe that I would lose a part of my moral identity if I were no longer permitted to do this. Notwithstanding, the agenda we are addressing here is scientific evidence taking precedence over inclinations and personal preferences arising from one's own biography. There are many examples of this. Instead of supporting people affected by a landslide in Switzerland, where we need have no doubt that they will be helped by insurance companies and the like anyway, we could make the same money available to, say, providing malaria 
nets for children in Ghana. In examples such as these, there is no doubt about the right course of action - though they are about isolated decisions.

Things are more difficult when we are not looking at isolated decisions but where people take up this reasoning and say: instead of just earning some money and then maybe donating a bit of it, I will try to earn as much money as possible and then donate far more, and do so as efficiently as possible. They then take good jobs to earn as much money as they can, so that they can then help as many people as they can. People like that do exist. I do not think there is very much we can say against their approach, but I must consternate that I find it very hard to comprehend. I do not understand how people can choose to live their lives like that. But some do, and we have to respect their choice.

I would now like to outline two problems I see here. A few moral psychological considerations will play a role that may raise a few eyebrows among hard-nosed philosophers. What I shall not be discussing is the foundations of EA. As I perceive it, most effective altruists view are committed to a form of utilitarianism. Their goal is as much happiness as possible for as many people as possible, as little suffering for as many people as possible, and all of this as efficiently as possible. This is the classic utilitarian calculation. But I do not wish to discuss utilitarianism here, even though I like many things about that philosophy. I would simply like to pick out two points that I believe to be inspired by utilitarianism, without examining the underlying moral theory.

When preparing for this lecture, I struggled, or should I say read my way through dozens of blogs. And I came across some things which were very alien to me, even incomprehensible. They bring me to a rough outline of my first hypothesis. I am not saying that they are all necessarily genuine, but I encountered such entries so frequently that I do not believe it to be a coincidence. To give you an example, I was reading one blog entry where somebody asked into the forum, so to speak, what the others thought about the idea of spending Sundays just hanging out with one's friends. Others replied - the discussions are always very earnest - and a conclusion was reached fairly fast: it is alright to hang out for a while, but too much hanging out means spending time just sitting around and chatting, and that is not really an efficient use of time considering the current state of the world. You really can read posts like that. I read a countless number of them. Another example entered the existential dimension. One blog contributor had a work contract where he was paid for his work according to output. And he was asking whether he should work as hard as possible in order to be able to donate as much as possible. The ensuing discussion 
was really quite endearing and reached the conclusion that maybe it would be better to work slightly less in order not to risk a burn-out. And why? I would have said so that he could still have a half-decent life. But no, the reason stated was so that he would still be in a position to continue donating in the future!

I know that some of you will be familiar with such discussions. I was not. I did know that such things existed, but, for me, it was like discovering the existence of a foreign tribe and then somehow trying to make sense of it. We should remember that these were closed chats and maybe not how philosophers would publicly discuss such things. But it did reveal to me how some people address such issues. On the one hand, I had to admire their really strong sense of discipline and moral asceticism in the light of a superordinate goal. There is evil in this world, and it is our duty to do all we can to ensure that people with a bad life get a better life. I also surmised, at least in part, that an individual's happiness counts primarily insofar as it serves to protect their ability to improve the world. A further feeling was that no space exists which is free of morality. Every action is morally relevant regarding the needs of others. A simple example might be: should I spend 30 dollars on seeing a movie and eating a burger, or should I donate that money? I can imagine doing that, and in a moment I will say why. When I read discussions such as these, I have the impression that people are putting in a great deal of effort. And yet, on the other hand, I also feel a little sad. These people seem to be under a kind of permanent moral stress, and I feel sorry for them. They spend all day, every day, deliberating whether or not they are on the right side. A kind of epistemic overtaxing takes place. Not only do they have to help, but they also have to help efficiently. And it is not so easy to determine whether it is more efficient to work two hours longer and earn more money, which can be donated now, or not to work those two hours and to lie on the sofa in order to be strong the next day and fit to earn more money, which can then be donated later. Maybe I am exaggerating, but that really is how it came across.

My hypothesis about this is as follows: if improving the world or doing good is such a dominant concern, and if there is no other understanding of a good life - in areas where morality is secondary - then people become degraded to morality machines, and that is not the meaning of life. Stating that it is the goal of human life to do as much good as possible is, in my opinion, wrong. I do believe that in order to lead a meaningful life, we must help, must donate, but we should not turn into morality machines. 
My observation is that this results in an instrumentalisation of enjoyment and self-care. Both are primarily relevant regarding the superordinate goal of improving the world: "to make the world a better place", that is the background here. And I had the impression - but one requiring some discussion - that effective altruists are not really interested in classical or modern conceptions of what constitutes the good life. Morality does play an important role - from Ancient traditions to Modernity - in what constitutes a good life, but not the only role.

I had a conversation with Dominic, my co-organiser today, in which we discussed a fascinating text. We were talking about the Puritans and how this mindset strongly reminded me of them. And he (as mentioned above) drew my attention to John Wesley, the founder of the Methodist movement. There was a wonderful sermon entitled "The Use of Money". Its motto is: "gain all you can, save all you can, give all you can". Earlier on in my lecture, I told you that Wesley maintained the same unchanging - not very high - standard of living his entire life in order to be able to donate as much as possible. This is precisely contained within the motto: "gain all you can, save all you can, give all you can". Nowhere does it say that we could enjoy our life. That is simply not the issue. And this is what makes the above discussion fit very well into the Puritan landscape.

Around the same time, the Puritans in the United States were having analogous thoughts, but they were not concerned with supporting the poor. Instead, the American Puritans interpreted earning money and being successful as a sign of being loved by God. And because they were not allowed to consume their success, they either had to donate it - John Wesley's option - or invest what they had gained in order to make more money - the spirit of capitalism as identified by Max Weber.

Historically speaking, this Christian tradition had no understanding for enjoyment or the like. This is why I enjoy telling people that I am a hedonistic Protestant.

There is another very nice example from the Bible. You probably all know the story of the anointment of Jesus in Bethany shortly before he dies. A woman comes along with a little bottle of perfume and pours it over his head, and in one version also over his feet. The disciples then say: could we not have rather used this money for the poor amongst us? They were the effective altruists of their time. And what does Our Lord say? - He says: "leave her alone. Do not embarrass her. She did a good deed." And that was truly the aesthetic element. In John 12 there is an analogous story. There it says that the woman wiped his feet with her hair, and that the house was filled with the fragrance of the perfume. The way that Jesus deals with this 
scene is very interesting. He says that physical attention - even one that costs money - can occasionally be more important than supporting others. I was fascinated to learn how Alex Rattee, a member of EA for Christians, interpreted this story:

"I want to suggest that the value Jesus expresses about the woman's actions should
actually spur us on in the effectve altruist desire to alleviate poverty efficiently, for
alleviating poverty may be one of the best ways to show Mary-like devotion to Jesus,
given that he is no longer with us in bodily form."

Here, then, this sensual, physical event is transformed into a spiritual devotion by this woman for Jesus. And when Jesus has gone, when his body ceases to exist, we no longer need to honour him thus. Then the best and quickest way to honour him is by supporting the poor. This is a kind of reversed biblicism: you take the Bible and pick out the stories you want and then twist them around until they fit your intended purpose.

An additional problem that I see here is the impartiality that is repeatedly demanded. I believe that, in a non-ideal world, it is not possible to speak to people about moral issues in this way. And my question to the effective altruists is therefore: instead of demanding from people impartial, effective aid and, in so doing, losing those people - because you are de facto demanding of those people that they detach themselves from all that makes them who they are, their relationships, their emotions - would it not possibly be even more effective to allow people to donate non-effectively, rather than to lose them altogether and have just a few remaining who donate effectively? This is a question that could well be in line with EA. Maybe, in order to be a truly effective altruist, one has to be able to forget EA.

The second point in this context is the stamina of effective altruists. I found a small-scale study about how long people can endure living as effective altruists. I do not think any comprehensive studies on this topic exist. I question how many of those who make the commitment are still committed more than five years later. I would be prepared to bet on there not being many, and the reason is that this philosophical setting alienates people from their emotions and their partiality.

My hypothesis is that people like donating, and that they like doing so for the communities to which they belong. Impartiality uproots people and has a negative impact on their willingness to help. I am always willing to take a stand against EA because I believe its consequences are not only 
negative, but morally fatal. But once again, that is an empirical hypothesis that requires investigation.

The question is, of course, why should impartiality be considered so important, and relationships, emotions, feelings be pushed aside? Why should we not be allowed to take our own communities into consideration when making donations? There is a major ongoing debate about whether or not one should donate to the church to which one belongs. What does the effective altruist say? Of course not. Donations should be directed where they make a difference. In my eyes, this is pure alienation. And why? My theory is that such people are predominantly male and young, and that worldwide they comprise a few thousand rationalistic utilitarians. They might be able to get excited about impartial effectiveness, but nobody else can. Incidentally, if anecdotal evidence of this is required, we only need to look at the footage of nerds making up panels at effective altruist conferences.

Now, just briefly, let us turn to the second challenge in conjunction with donations: paternalism. We know what would be good for others; we know how things can be made better. Donating often leads to problems not really being solved. We can see this, for example, with the refugee situation. Once a refugee camp has been set up, it has to be supported further. The people who live there seldom become able to build up their own existence. This is a problem. Angus Deaton illustrated this very well in his book The Great Escape. I do not want to go into detail here; suffice it to say that a large part of development aid from western states, and also from western NPOs, is money that goes down the drain. As a result of generous donations by individuals, coupled with a large amount given by states, the pressure on corrupt governments is lessened and they can use the small amount of money they do have at their disposal for other things - impressive palaces, the military, whatever. Bad governments can govern without the consent of society because they have money, and they have it because of development aid, and that money comes from the governments of other countries and via aid organisations. And, last but not least, there are correlations - not causalities - which show that development aid could actually be a problem. The states with the most development aid over the last 30 years tend to be the states with the smallest economic growth and the worst democratic development. The numbers are really interesting.

This leads us to the question: what is the point of donating, especially with regard to development aid? I would like to mention an option which could be given attention - without maintaining with any certainty that it is a good alternative. Aid must be employed in order to help people 
to become independent. And how do we best do that? One possibility increasingly in the focus - albeit not nearly enough in church circles - is to attempt to locally reinforce entrepreneurship, for example via microcredits. Why? In these situations, it is usually the case that there are too few jobs enabling people to earn money. This is why it is important to empower individuals so they can start a small business and build up something akin to an autonomous life. For me, investment - in the true sense of the word - in foreign companies goes in the same direction. Economic development is then facilitated, which cannot be a bad thing. It means investing as an individual in companies that score well in terms of human rights and the environment. This is not donating as such, but it could also help. And a debate about this issue is currently ongoing.

To conclude: helping others is a moral obligation, with latitude available as to how we fulfil this obligation. Donating is one possible way of fulfilling it. Providing help and donating money are constituent parts of the good life, not its main objective. My motto, in summary, would be: donate generously, with an occasional nod to efficiency, and wherever possible, do not forget social investing.

\section{References}

Deaton, Angus. The Great Escape: Health, Wealth, and the Origins of Inequality. Princeton, Oxford: Princeton University Press, 2013.

Giving What We Can. "Pledge to give more, and give more effectively." Accessed 3 September 2021. https://www.givingwhatwecan.org/pledge.

Mieth, Corinna. Positive Pflichten. Berlin, Boston: De Gruyter, 2012.

Singer, Peter. "Famine, Affluence, and Morality." Philosophy and Public Affairs 1, no. 3 (1972): 229-243.

Klatzer, J. "Haben moralische Verantwortung, allen Menschen zu helfen." Kurier, 3 August 2016. https://kurier.at/wissen/moralphilosoph-peter-sin ger-im-gespraech-haben-moralische-verantwortung-allen-menschen-zu-h elfen/212.770.745.

Rattee, Alex. "Alabaster Jars \& Optimising." A blog for the Effective Altruism for Christian community. 18 January 2017. https://eachdisc ussion.wordpress.com/2017/01/18/alabaster-jars-optimising/.

Zewo. "Spendenland Schweiz." Accessed 3 September 2021. https://zewo.c h/wp-content/uploads/2019/06/Spendenstatistik-2017.pdf. 
